\title{
Investigation of Scale Inhibition Mechanism by Electrochemical Quartz Crystal Microbalance
}

\author{
Yuan Lu ${ }^{1}$, Qiang Wei ${ }^{1}$, Yan Cheng, Xiedong $\operatorname{Ren}^{2}, H u W^{2,3, *}$, Juan Xie ${ }^{2, *}$ \\ ${ }^{1}$ CenerTech Oilfield Chemical Co., Ltd., CNOOC, Tianjin, 300450 \\ ${ }^{2}$ School of New Energy and Materials, Southwest Petroleum University, China, 610500 \\ ${ }^{3}$ Research Centre of Corrosion and Protection for Materials in Oil and Natural Gas exploitation, \\ Southwest Petroleum University, China, 610500 \\ *E-mail: hwang@swpu.edu.cn (Hu Wang); jxie@swpu.edu.cn (Juan Xie)
}

doi: $10.20964 / 2021.05 .38$

Received: 26 November 2020 / Accepted: 21 January 2021 / Published: 31 March 2021

\begin{abstract}
In this paper, electrochemical quartz crystal microbalance (EQCM) was applied to evaluate scaling and scale inhibitors by applying cathodic potential (potentiostatic polarization) on working electrode (quartz crystal microbalance wafer). The mass variation of scale deposited on wafer surface was in situ monitored by the EQCM. The scaling kinetic parameter and inhibition efficiency in the presence of scale inhibitor were obtained. Scaling in static and dynamic conditions of four tested scale inhibitors, POCA, HEDP, ATMP and SHMP, had been studied. All the inhibitors exhibited remarkable inhibition performance, with the inhibitor concentration ranging from $1 \mathrm{mg} / \mathrm{L}$ to $20 \mathrm{mg} / \mathrm{L}$. Adding scale inhibitor during the scaling process displayed much better inhibition effect than adding it preferentially. Inhibition mechanism of four inhibitors is quite different, which can be revealed by combining accelerating scaling experiment, SEM and XRD.
\end{abstract}

Keywords: A1. Crystal morphology, A1. Nucleation, A2. Electrochemical growth, B1. Calcium compound, A3. Quartz crystal microbalance

\section{FULL TEXT}

(C) 2021 The Authors. Published by ESG (www.electrochemsci.org). This article is an open access article distributed under the terms and conditions of the Creative Commons Attribution license (http://creativecommons.org/licenses/by/4.0/). 